\title{
Estimation of surplus energy in off-grid solar home systems
}

\author{
Satyam Bhatti* and Arthur Williams \\ Department of Electrical and Electronic Engineering, University of Nottingham, Nottingham, UK
}

Received: 28 June 2021 / Received in final form: 7 July 2021 / Accepted: 7 July 2021

\begin{abstract}
A recent survey shows that a large percentage of people living in underdeveloped countries do not have access to electricity and are isolated from the rest of the world. Solar energy can help meet the energy demand; however, it has an intermittent nature and relatively high installation cost. The improvement in offgrid Solar Home Systems (SHS) helped many people get access to electricity. However, systems are sized to meet demand on cloudy days, which results in significant wastage of available energy on sunny days, reducing the energy return on investment. This research paper discusses the load requirement of the people living in rural locations. It uses data collected over the last year by collaborating organisations, providing detailed load and solar charging data for off-grid households in Odisha, India. This dataset is analysed to understand the working principle of the installed SHS and the typical daily load profile. Next, the solar data is compared with solar data from online accessible software on an hourly basis and on a 5-minute scale to evaluate the surplus energy. The data shows a significant surplus of solar energy for most of the year that could be used for other low-powered devices. Various methods are discussed to detect surplus energy available during the daytime based on the provided solar data.
\end{abstract}

\section{Introduction}

As per World Bank Data, access to electricity is variable across the world. Moreover, access to electricity in developed countries is $97.4 \%$, whereas in underdeveloped countries is only $78.7 \%$, i.e., lack of access to electricity is eight times higher in less developed countries [1]. In countries like India, Bangladesh and Pakistan, around 40\% of the population do not have access to electricity, mostly in rural areas, while in Uganda, Rwanda and Tanzania, it is $73 \%, 71 \%$ and $67 \%$, respectively [2].

Lack of access to electricity leads to a lot of problems for people living in rural locations. Most of their electricity requirement is during the night to provide light while cooking food or studying. Without electricity, women give birth in darkness or without proper medical appliances [3]. This rural group lacks access to telecommunication; provision of electricity is crucial for economic development, and hence access to it is vital for all.

Hence, researchers around the globe are working on efficient off-grid systems that can help reduce the cost of electricity. It is predicted by the United Nation's Sustainable Development Goals that by 2030 there will be around

\footnotetext{
* e-mail: satyam.bhatti29@gmail.com
}

100,000 mini-grids installed, and one-third of rural communities will have access to electricity through off-grid systems [4]. Solar energy will be used as the predominant power source for these rural households.

The demand for solar energy has increased fourfold across the world from 2016 to 2020 due to its tremendous benefits to the client, such as its environment-friendly nature, low maintenance and having no fuel cost [5]. Solar energy is a free and abundant resource, which has led to rapid growth in PV panel installation both on and off-grid. However, solar energy is generated during the daytime, whereas the primary energy demand by rural households is usually during the night [6].

Besides these challenges, people living in underdeveloped countries face poor connectivity to the grid or increased charges for electricity. People follow the hourly based tariff system or the Pay as you go method to purchase electricity in rural locations. As a result, they may have excess solar energy during the day when rates are cheaper, whilst paying more at night [7]. Since most solar home systems (SHS) operate off-grid, they are installed with batteries to meet the electricity demand in the absence of the sun. The battery's cost, maintenance, and life cycle are another big hurdle for people living in rural locations [8]. 
Due to high costs, the batteries in many off-grid SHS are insufficient to store all of the excess solar energy for use at night. Its intermittent nature results in wastage of solar power generated from 11 am to $2 \mathrm{pm}$ when irradiance is maximum, but load consumption is negligible [9]. The excess solar energy generation is predicted to be as high as 500 Wh per month, enough to operate devices with low power ratings [10]. Therefore, there is a need for an algorithm to detect the surplus energy generated during the day and efficiently utilise that surplus.

A significant number of papers present evidence for the benefits of off-grid solar in rural communities and caution about the basic level of service provided (essential lighting) and the difficulty in covering costs [11]. A detailed case study research by Eras-Almeida et al. [12] explains the benefits of improved technology such as LEDs and integrated charge controllers. Still, it highlights the limits of policy support and financial sustainability for SHS.

Reducing wasted energy can be very useful for people living in underdeveloped countries whose energy requirements are low [13]. A charge controller plays a vital role in SHS in utilising the available energy and protecting the battery, but the latest electronic charge controllers may be too expensive. Using an advanced charge controller will increase the overall cost of the system but could significantly reduce losses because they incorporate Maximum Power Point Tracking. Standard household electrical loads have an AC input, while the energy output from a solar panel and the battery is a DC output. Basic inverters can have significant losses or cause additional losses due to poor waveform. Advanced inverters, if they are available, are expensive, which may contribute to an increase in the overall cost of electricity.

Some governments of underdeveloped countries have policies to sell solar panels at a subsidised price for off-grid use to help the economically weaker section of society to benefit from clean electricity. However, the overall cost of SHS includes other electrical components such as a charge controller and batteries. The batteries available in the market are relatively expensive or have a short life span, which requires maintenance or replacement at regular intervals [14]. Hence, on an individual scale, rural households struggle to afford the higher cost of off-grid power and often lack access to electricity. Nevertheless, a recent paper by Thomas et al. [15] describes how SHS of 20 or $50 \mathrm{Wp}$ has brought benefits to households in refugee camps in Rwanda, especially when using Pay-as-you-go technology. They conclude that this approach creates an adequate local support infrastructure for disseminating and maintaining the systems.

Johannes Urpelainen et al. [16] investigated the commercial viability of installing SHS in a rural location and analysed data at a new energy centre for six months in 2014. Their research was partnered with an Indian Social enterprise Boond Engineering and Development, which provide an affordable and high-quality solar product at rural locations of north India. Boond concentrated on selling solar products based on household load requirements. The research showed that more people purchased $100 \mathrm{~W}$ than $40 \mathrm{~W}$ panels due to demand for more power by those who purchased SHS and lack of finance for poorer households. There was no assessment of the actual energy use.

Barman et al. [17] carried out a survey of users of SHS in Assam, India, which included an analysis of reliability, benefits and actual energy usage. They show that many of the systems were under-used, with typical lighting usage of 1-3 hours in winter and monsoon season, rising to $3-4$ hours in summer. No actual energy monitoring took place, but according to their study, the output was limited in many cases by the poor orientation or shading of the solar module or the poor state of the battery.

There is minimal data on the actual load consumption for SHS in rural locations in the existing literature. One paper from Colombia [18] shows detailed data for an offgrid solar system with an indication of surplus. Still, it is a study of a single household with a $1.3 \mathrm{kWp}$ system, so hardly comparable to SHS elsewhere. Some other case studies discuss the prediction of usage based on typical appliances, but few reports back on monitored use after installation. This paper, therefore, fills a critical gap in this research.

Many papers cover the control of grid-connected solar systems with energy storage, but few publications cover the control of off-grid SHS. Researchers from Pakistan propose connecting SHS together with energy storage to enable surplus power to be delivered to community loads [19]. Although this is an interesting approach, it requires significant additional infrastructure to connect households and energy storage together with the central controller.

The research aims to evaluate the quantity of surplus solar energy generated in off-grid systems. One objective is to identify the patterns of surplus generation to see if this surplus could be easily put to use. To achieve the aim, the researchers analysed various load consumption data for households with solar generation.

The primary source of data was from a company that has been monitoring solar home systems installed in the Indian state of Odisha, one of the regions with the lowest access to grid electricity. This data is studied and analysed to understand solar patterns and load profiles. The total solar energy generated is calculated from the data available online through NASA and Solcast. The overall solar home system parameters like the battery performance, state of charge and depth of discharge are examined to understand the practical operation of the SHS.

The research paper develops a method to estimate surplus energy generated each day for SHS and applies this to data from Indian households. Further, the article evaluates the surplus energy available in a year based on the seasonal patterns (summer, rainy and winter) and discusses methods of detecting the surplus energy generation. Lastly, different ways are mentioned by which the client can use surplus energy efficiently.

It is intended that this work should be beneficial to people living in remote areas who rely on small solar systems for access to electricity. By using currently surplus energy, it will improve the cost-effectiveness of solar home systems. The energy return on investment of the SHS can also be improved. 


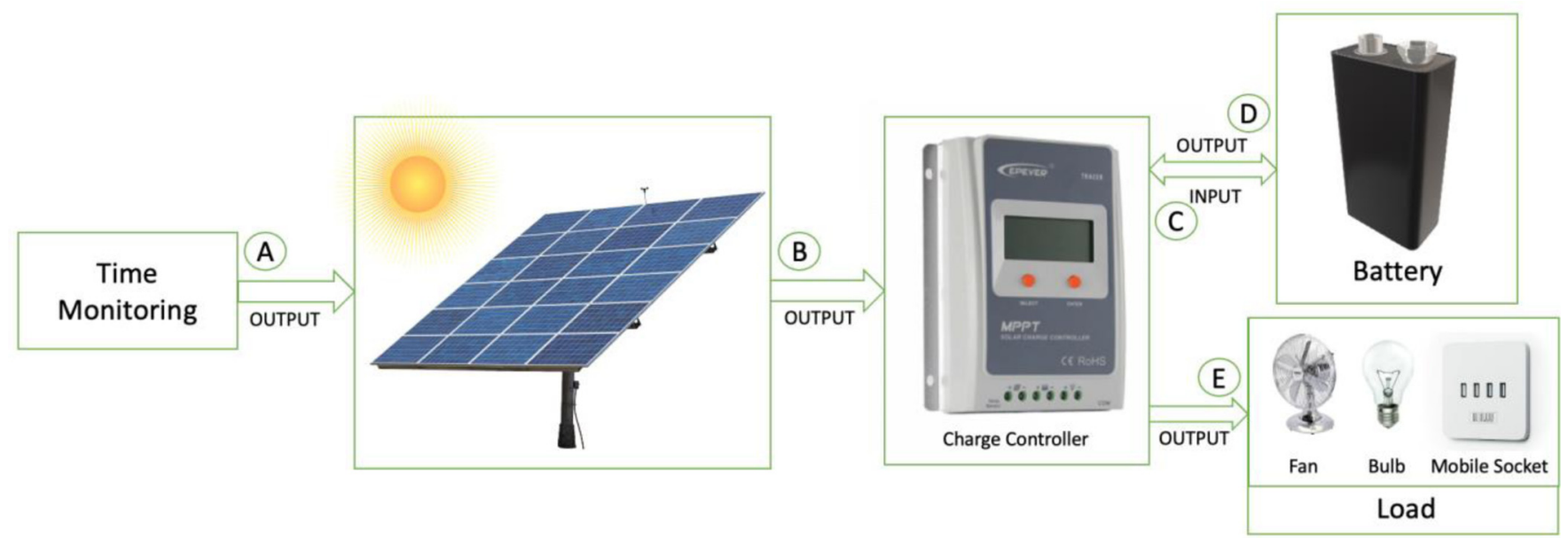

Fig. 1. The flow of energy diagram for the household installed at Odisha, India.

\section{Explanation of datasets}

The solar data access was initiated by company CREATIVEnergie, based in Edinburgh, United Kingdom [20]. The primary dataset used was provided by their partner company Connected Energy, based in Scotland and India [21] through the collaboration with a partner in Odisha, NE. India. The solar data depicts the set of values for the solar output, load consumption and the characteristic battery values of off-grid SHS situated at four locations in Odisha. This SHS data from the company is compared with the solar radiation data, accessible from online sources on an hourly basis and on a 5-minute scale. Additionally, the practical impact of the operation of the charge controller, which controls the flow of energy from the solar to battery and load, is clear from the data patterns.

The researchers analysed the data for existing SHS installations, two sets from urban locations (Bhubaneswar and Cuttack), while the other two are from households in rural areas (Udala and Mayurbhanj). The data for the SHS are recorded as instantaneous values of power and cumulative values of energy taken directly from the sensors installed in the SHS saved on software known as Cloud Solar [22]. These values were downloaded from the software, and the data was provided in the UK standard time. However, the location of the SHS is in India; hence, the time zone was converted from the UK time zone to the Indian time zone. This required an adjustment from 5:30 hours ahead in the months from November to March or 4:30 hours in the months of June and July (during British Summer Time).

The two sets of data, one from the cumulative energy meter and one for instantaneous power, were provided on the load and the solar side. In between the data points, which are mostly taken at around one-hour intervals, step changes in power are not shown. Average power can be determined from the change in energy, and this is sometimes quite different from instantaneous power (load and solar) readings. Even with a one-hour time-lapse, the difference between each energy reading is often minimal.
Hence, there is limited accuracy in the average power over that period. For a few days, data at 2-4-minute intervals were available. This has been analysed in more detail to check the validity of results based on hourly data.

\subsection{Electrical measurements}

\subsubsection{Signal strength}

A data logger is used to record values at point (A) in Figure 1. Signal Strength values monitor the accuracy of the data collection. If the signal strength changes drastically (such as it goes down to zero), it is an indication that the data logger is not sending the data correctly.

\subsubsection{Solar data}

A set of instantaneous electrical power values and a cumulative energy reading (to the nearest $\mathrm{Wh}$ ) are recorded at point (B) in Figure 1. Each solar panel is installed on the rooftop of households at the four locations in Odisha. The solar panel in urban households has a solar capacity of $60 \mathrm{~W}$ or $80 \mathrm{~W}$, whereas the rural households have a power of $40 \mathrm{~W}$.

\subsubsection{Battery characteristics}

The data includes instantaneous values of the battery voltage, battery temperature, state of charge, battery power and cumulative energy - both charging (C) and discharging (D). The data indicates that the default minimum battery voltage is $11.7 \mathrm{~V}$, and hence, the $12 \mathrm{~V}$ is the standard battery voltage at normal working conditions.

\subsubsection{Load consumption}

The load data includes instantaneous power and cumulative energy values, recorded by the sensor installed at point $\mathrm{E}$ in Figure 1. The power values are registered to the nearest $\mathrm{mW}$ but sometimes showed small or negative values (in the range $-1 \mathrm{~W}$ to $+1 \mathrm{~W}$ ). There are, therefore, some limitations to the accuracy of sensors while recording 
the load power. Energy meter readings are given to the nearest $\mathrm{Wh}$, so there is no change in the cumulative energy value in some hours.

\subsection{Role of the charge controller}

The Cloud charge controller is an internet-enabled solar controller that monitors the battery voltage, current and ambient temperature to control the charging of the battery within recommended parameters. As with many charge controllers, a standard chip is used to control battery charging in three stages. A maximum power point tracker extracts optimum power from the solar module during the bulk charging stage to provide a high charging current until the battery voltage comes to a certain level (adjusted for temperature). When it reaches $13.5 \mathrm{~V}$, the controller swaps to the topping stage at a constant voltage. After the topping stage, if no load is applied, the controller swaps to trickle charging. Additionally, the charge controller functions to protect the battery when there is no solar input with a low voltage disconnect circuit limiting the load when the battery voltage falls to a minimum value.

From the data, it is clear to see that after sunrise, solar power feeds the load and battery, up to the point that the battery is full, which is detected by the increase in battery voltage. During the topping stage and trickle charge, the current is reduced. Despite the maximum power point tracker, the solar output will be limited to supplying the required current. Once the battery is fully charged, the operation moves away from the maximum power point. When a load is connected, it is effectively powered directly from the solar, so the current from the solar module increases and decreases with the load. If the load current demand is more than the module can supply, additional current is supplied from the battery, recharged as soon as the solar output is greater than the load current.

\subsection{Solar resource data}

\subsubsection{Data from NASA on an hourly scale}

The set of real-time data is compared with the solar irradiance values, which are available from websites. One of the freely accessed solar data websites is NASA [23] which uses interpolation between an array of earth monitoring stations to calculate the solar irradiance available at any particular location, based on latitude and longitude to the nearest $0.5^{\circ}$.

The solar data is given for Bhubaneswar, Udala, Mayurbhanj and Cuttack in Odisha to predict solar energy generation theoretically. The location coordinates are set on the NASA website to get the hourly radiation data. In the same section of the NASA website, some parameters are selected, such as the time range (i.e., January, February, March, June, July, November and December for the year 2020), Mounting type (fixed), the slope of the installed solar panel $\left(20^{\circ}\right)$ and the azimuth $\left(0^{\circ}\right)$. In addition, the type of solar cell is also mentioned in the same section. For the rural locations, a Silicon solar module is installed at the household with a peak PV power of $40 \mathrm{~W}$. After setting these parameters to the system, the overall excel sheet is downloaded to get the solar energy generation at each location. However, for this research, the NASA data was only helpful for average radiation values since the data for 2020, when SHS monitoring took place, is not yet freely available.

\subsubsection{Data from Solcast on 5 minute scale}

Another software is Solcast [24] which provides solar irradiance on a minute scale for many locations worldwide. Typically, access to the software is for commercial users. However, Solcast offers a credit of AUS $\$ 600$ for University research, which was used in this case. Solar radiation data is available at a one-minute time resolution for a location at Bhubaneswar, the state capital of Odisha, throughout the year 2020.

\subsubsection{Reasons for not choosing other software}

Software such as PVgis and PVsyst are easily accessible and provide a free source of solar data sets. However, they both use solar radiation values directly from NASA. Hence, there is not much difference in the data set values taken from the PVsyst or PVgis compared to the NASA website. A limitation of this software is that they require known values for cloud cover and clear sky index, and therefore, they have not been used for this study.

Another relevant software is HOMER (Hybrid Optimization Model for Electric Renewables), designed to estimate the overall cost and optimisation of renewable energy, including solar systems. Many researchers have used HOMER to estimate the hourly load consumption of households along with the hourly solar energy generation. However, HOMER estimates load based on a statistical algorithm, so it does not help estimate surplus energy from real-time data.

The third most relevant software used is RETScreen, which also uses NASA data to evaluate the solar resource. RETScreen provides information on the cost and reliability of renewable energy systems but is not helpful for the hourly or minute-wise calculation of surplus solar energy.

\section{Evaluation of energy surplus from SHS examples}

\subsection{Daily data examples}

As explained above, there were a few days and locations where electrical data was available with time steps of 2 to 4 minutes through most of the day. These could be plotted alongside the solar data from the 5-minute Solcast dataset. The Solcast data was used to determine the solar power input based on the known rated peak-Watts of the solar module. As this detailed electrical data was only available for a limited number of days and locations, the overall evaluation of surplus solar energy also used many days with hourly data. The following graphs show a clear relationship between solar input, solar output and load variation. The data at a 5-minute resolution has been used to validate surplus based on hourly data. 
Table 1. An example of the data set for rural location on 5th Jan, 10-11 am.

\begin{tabular}{|c|c|c|c|c|c|c|c|c|c|c|}
\hline $\begin{array}{l}\text { Time } \\
\text { (hrs) }\end{array}$ & $\begin{array}{c}\text { Battery } \\
\text { Temp } \\
\text { (॰c) }\end{array}$ & $\begin{array}{c}\text { Battery } \\
\text { Voltage } \\
\text { (V) }\end{array}$ & $\begin{array}{c}\text { Load } \\
(W)\end{array}$ & $\begin{array}{l}\text { Solar } \\
(\mathrm{W})\end{array}$ & $\begin{array}{c}\text { State of } \\
\text { Charge } \\
(\%)\end{array}$ & $\begin{array}{c}\text { Signal } \\
\text { Strength }\end{array}$ & $\begin{array}{l}\text { Total } \\
\text { Input } \\
\text { (Wh) }\end{array}$ & $\begin{array}{c}\text { Total } \\
\text { Output } \\
\text { (Wh) }\end{array}$ & $\begin{array}{c}\text { Battery } \\
\text { Charging } \\
(W h)\end{array}$ & $\begin{array}{c}\text { Battery } \\
\text { Discharging } \\
\text { (Wh) }\end{array}$ \\
\hline 10:01:01 & 25.36 & 13.48 & 0.64 & 7.44 & 100 & -107 & 25 & 9 & 3 & 1 \\
\hline $10: 02: 37$ & 25.36 & 13.46 & 0.64 & 7.44 & 100 & -105 & 26 & 9 & 3 & 1 \\
\hline $10: 04: 46$ & 25.36 & 13.45 & 0.00 & 7.43 & 100 & -107 & 26 & 9 & 3 & 1 \\
\hline $10: 06: 25$ & 25.36 & 13.45 & 0.64 & 7.21 & 100 & -107 & 26 & 9 & 4 & 1 \\
\hline $10: 20: 22$ & 25.78 & 13.19 & 0.63 & 2.79 & 100 & -105 & 27 & 9 & 5 & 1 \\
\hline $10: 22: 08$ & 25.36 & 13.18 & 0.63 & 2.57 & 100 & -103 & 27 & 9 & 5 & 1 \\
\hline $10: 26: 20$ & 25.36 & 13.17 & 0.62 & 2.57 & 100 & -105 & 27 & 9 & 5 & 1 \\
\hline $10: 28: 00$ & 25.36 & 13.17 & 0.62 & 2.99 & 100 & -111 & 27 & 9 & 5 & 1 \\
\hline $10: 29: 56$ & 25.36 & 13.20 & 0.63 & 3.43 & 100 & -105 & 27 & 9 & 5 & 1 \\
\hline $10: 37: 23$ & 25.78 & 13.29 & 0.63 & 4.10 & 100 & -105 & 28 & 9 & 5 & 1 \\
\hline $10: 37: 26$ & 25.36 & 13.26 & 0.63 & 4.09 & 100 & -105 & 28 & 9 & 5 & 1 \\
\hline $10: 39: 52$ & 25.36 & 13.28 & 0.00 & 4.32 & 100 & -103 & 28 & 9 & 6 & 1 \\
\hline $10: 55: 11$ & 25.78 & 13.52 & 0.64 & 5.93 & 100 & -107 & 28 & 9 & 1 & 1 \\
\hline $10: 55: 14$ & 25.78 & 13.53 & 0.64 & 5.93 & 100 & -107 & 28 & 9 & 1 & 1 \\
\hline $10: 55: 18$ & 25.78 & 13.49 & 0.64 & 5.91 & 100 & -107 & 28 & 9 & 1 & 1 \\
\hline $10: 57: 09$ & 25.78 & 13.56 & 0.64 & 6.39 & 100 & -101 & 28 & 9 & 1 & 1 \\
\hline $10: 57: 12$ & 25.78 & 13.57 & 0.64 & 6.39 & 100 & -101 & 28 & 9 & 1 & 1 \\
\hline $10: 57: 15$ & 25.78 & 13.57 & 0.64 & 6.39 & 100 & -101 & 28 & 9 & 1 & 1 \\
\hline $10: 57: 19$ & 25.78 & 13.57 & 0.64 & 6.39 & 100 & -101 & 28 & 9 & 1 & 1 \\
\hline $10: 57: 22$ & 25.78 & 13.53 & 0.64 & 6.37 & 100 & -101 & 28 & 9 & 1 & 1 \\
\hline $10: 59: 30$ & 25.78 & 13.66 & 0.65 & 7.54 & 100 & -103 & 28 & 9 & 1 & 1 \\
\hline
\end{tabular}

Three essential aspects of the surplus evaluation could be deduced from this data:

- The correlation of the solar input data from Solcast with the measured solar output evaluates the surplus energy when the module was operating at full efficiency.

- The operation of the charge controller within the SHS and delivery of solar power to load and battery. This shows clearly that when the battery is fully charged, the output from the solar is limited to supplying the instantaneous load.

- Accurate evaluation of the surplus for these days, compared with hourly assessment for the same days, enables the determination of the error due to the use of hourly averaged data for the other days and locations.

The data set consists of parameters such as time (hrs), battery temperature $\left({ }^{\circ} \mathrm{C}\right)$, battery voltage $(\mathrm{V})$, load consumption (W), solar (W), state of charge (\%), signal strength (Unit), total input/output energy (Wh) and battery charging/discharging (Wh) values which are recorded using the appropriate sensors. Table 1 depicts an example of the values recorded on 5th Jan between 10 and $11 \mathrm{am}$ for the rural household located at Udala, Mayurbhanj. It is not known how the state of charge is measured. In Table 1, the value is $100 \%$ even though it is clear that the battery is charging during this period. The value of a state of charge has not been used in our analysis.

\subsection{Surplus power for rural household}

The solar data for the rural location covers a period of two months (January and February 2020). Figure 2 shows a 48-hour time window as the energy pattern is nearly the same on other days.

For these 48 hours, the energy monitoring data was available with a short time resolution, so this has been plotted in Figure 2a showing instantaneous load (blue) and solar (orange) power generated by the $40 \mathrm{~W}$ solar panel. On the right hand, Figure $2 \mathrm{~b}$ shows the same data at hourly intervals, with averaged hourly solar and load. Below each graph are the corresponding values of battery voltage (green). Figure 2a shows that the maximum instantaneous solar power on 6th Jan is $17 \mathrm{~W}$ and on 5 th Jan is $10 \mathrm{~W}$. However, these peak values are reduced when taking the average over each hour to $14.5 \mathrm{~W}$ and $7.5 \mathrm{~W}$, respectively, as shown in Figure 2b. On 4th Jan, the data presented is for the evening only; there is no solar power generated after 16:19:00 on that day.

The main load power on 4th Jan was approximately $6 \mathrm{~W}$ for 1.5 hours. The value using short time resolution and hourly resolution is nearly the same. However, on 5th Jan, the load consumption has a much shorter time duration, as seen from the short time resolution curve. When averaged over an hour, the peak load demand of $6 \mathrm{~W}$ shows as only $2 \mathrm{~W}$ on the hourly averaged curve. In contrast, there is considerable daytime load consumption 

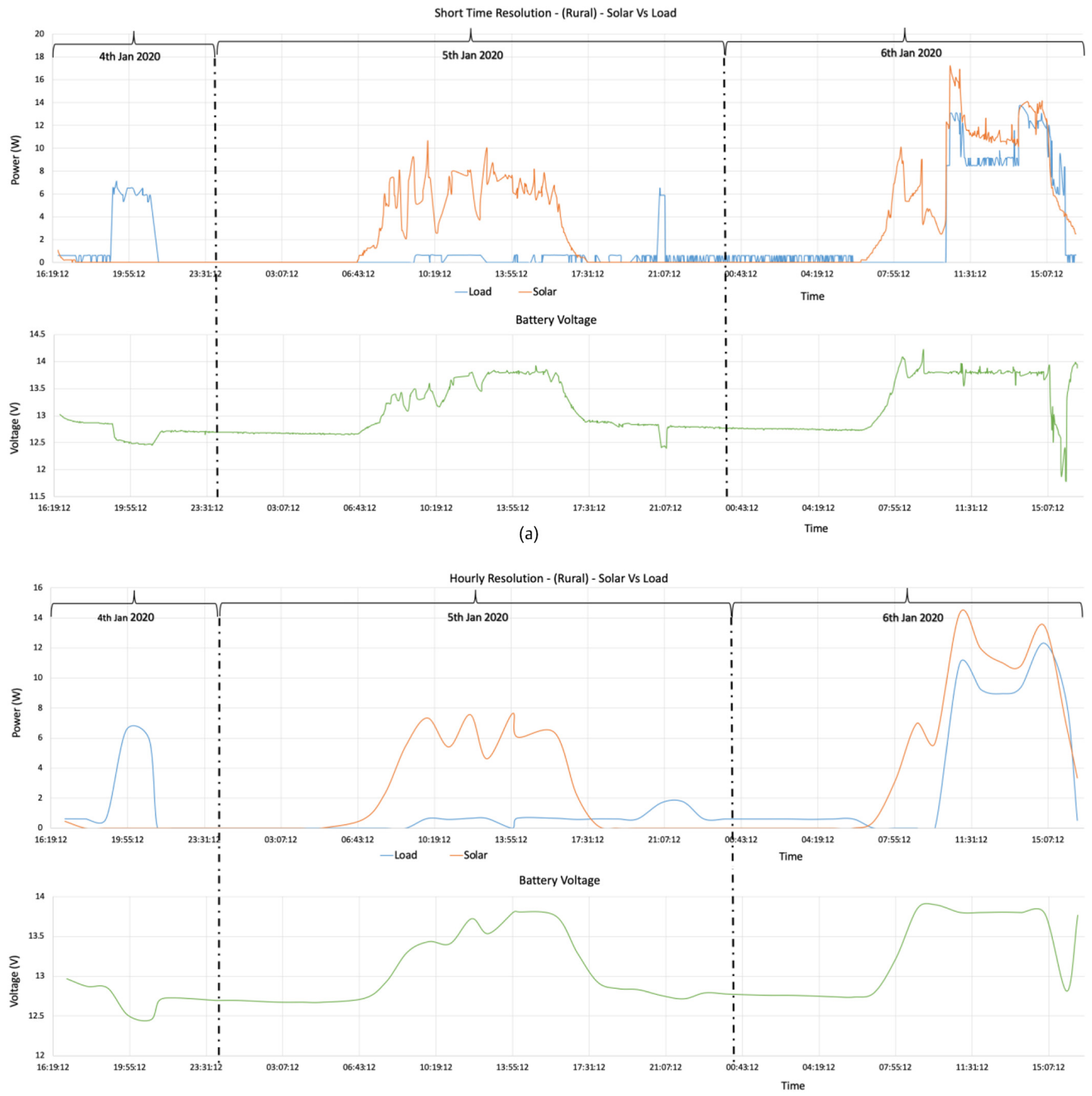

(b)

Fig. 2. Example of daily solar data for 4th Jan, 5th Jan and 6th Jan at the Rural location. (a) For short time resolution (approx. 5-minute); (b) For hourly resolution.

on 6th Jan, when the peak for short time resolution is $14 \mathrm{~W}$ while for the hourly resolution it is approximately $12 \mathrm{~W}$. The battery voltage of the SHS remains nearly the same when the short time resolution is compared with hourly averaged data, ranging from $11.7 \mathrm{~V}$ (minimum) to $14.3 \mathrm{~V}$ (maximum). As expected, the battery voltage increases during the day with the significant solar power generation, while it reduces when there is load demand in the evening with no solar input. The difference between solar input and daytime load, when the battery is fully charged, e.g., on 6th Jan after 11:00, indicates system loss due to the charge controller, which is approximately $14 \%$.

For evaluating the surplus energy, the solar output is compared with 5 -minute and hourly resolution solar power from the Solcast software for 5th Jan, and 6th Jan. Solcast provides solar irradiance values which were scaled according to the rating of the solar panel installed at the SHS to determine the potential solar generation. The orange curve 

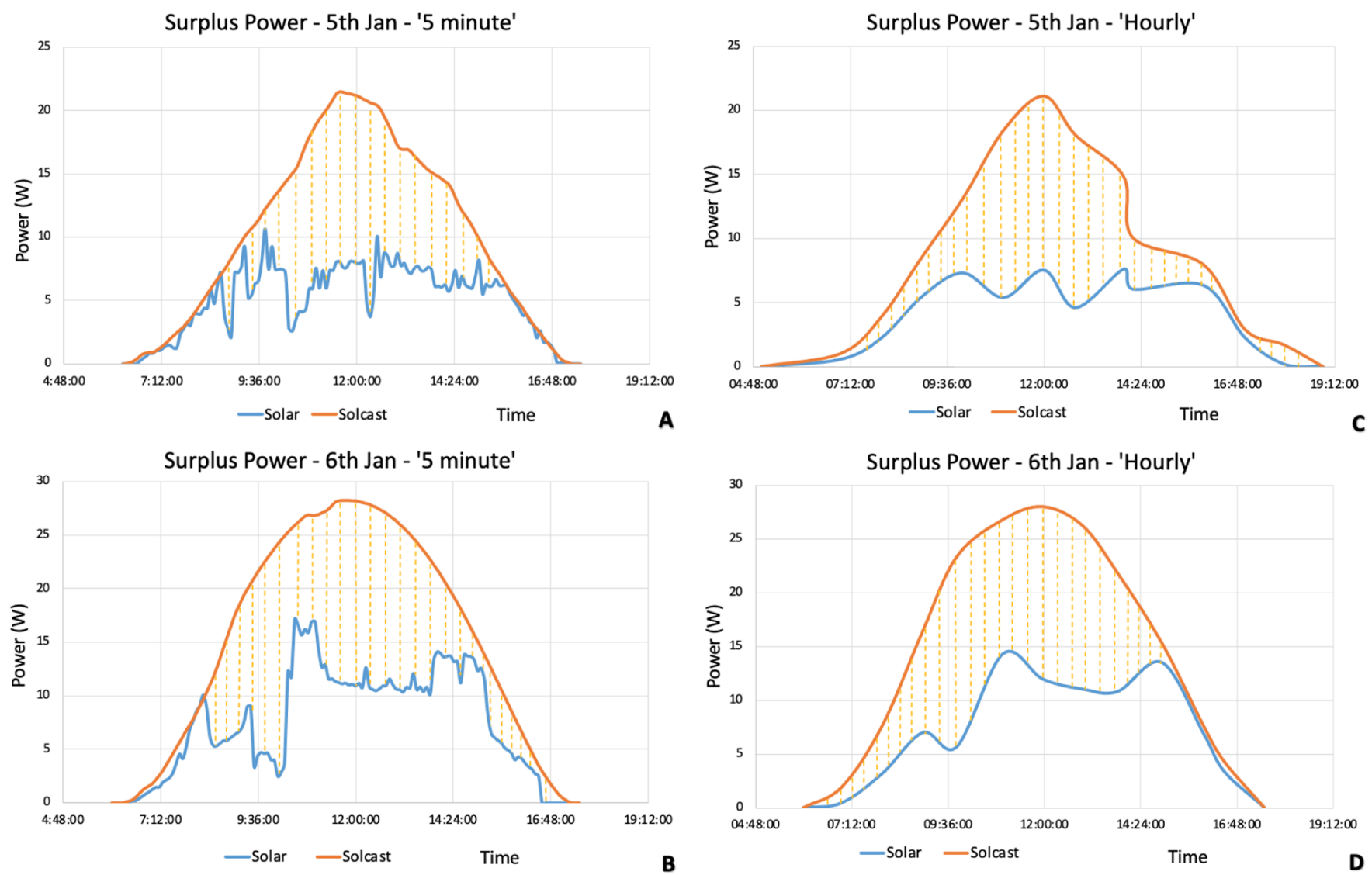

Fig. 3. Surplus Power on 5-minute; (A) 5th Jan; (B) 6th Jan \& on an hourly scale (C) 5th Jan; (D) 6 th Jan.

in Figure 3 represents the available solar power for the chosen location as calculated from the Solcast software. As can be seen, the real-time solar power (blue curve) is either near to or below the orange curve. Some power may be unavailable due to shading, but the main reason for the difference is that when the battery is full, the solar module output is limited to supplying trickle charge plus any instantaneous load. Therefore, the area between the orange and blue lines represents the surplus energy available from the SHS.

Figure 3 shows the evaluation of the solar surplus for the two daytime periods during the 48 hours analysed. When calculated using 5-minute data (graphs A and B), the total energy supplied by the solar module is $140 \mathrm{Wh}$, whereas the potential solar generation calculated from Solcast data is $291 \mathrm{Wh}$. Therefore, $151 \mathrm{Wh}$ or $52 \%$ of the solar output is surplus (unused) energy. Using the hourly resolution (graphs $\mathrm{C}$ and $\mathrm{D}$ ), the values determined are $144 \mathrm{Wh}$ of solar supplied out of a potential of $301 \mathrm{Wh}$, which gives a surplus of $52 \%$ again. Therefore, despite averaging the hourly data, the calculated percentage surplus is the same.

\subsection{Surplus power for urban households}

Another solar dataset provided by Connected Energy is for an Urban SHS at Bhubaneswar for the Summer season. The solar data relates to SHS with a $60 \mathrm{Wp}$ module for two months, i.e., May and June 2020. As with the rural data, there was only a limited set of data at short time resolution, whereas the rest of the data was taken hourly. A 48-hour period was available for detailed analysis, from 22nd to 24th May 2020. Figure 4 shows the comparison of the solar output (orange curve), load consumption (blue curve) and the battery voltage (green curve) for SHS. Figure 2a shows data taken at 2-to-5-minute intervals while the average (hourly) data is shown in Figure $2 b$.

The impact of averaging the data over each hour can be seen in the smoother curves in Figure $4 \mathrm{~b}$. The peak generation values are reduced by averaging, e.g., on 24th May, the maximum instantaneous value of the solar power is $30 \mathrm{~W}$ while the maximum average hourly value is $17 \mathrm{~W}$ during the same period. The significant short-term variations in solar output may be due to passing clouds, which occur in Odisha even during the summer months of May and June.

As seen from Figure 4, there is very little load consumption during the evening of the 22nd of May, i.e., only a maximum of $4 \mathrm{~W}$ was consumed that day. In contrast, the load demand increased in the evening of the 23rd of May, reaching a maximum of $6 \mathrm{~W}$, and the load is 'on' for 4 hours. The appliances used by these SHS have low power ratings, mainly LED lighting. For example, this urban household uses a LED bulb, fan and mobile charger with power ratings of $4 \mathrm{~W}, 6 \mathrm{~W}$, and $10 \mathrm{~W}$, respectively. 

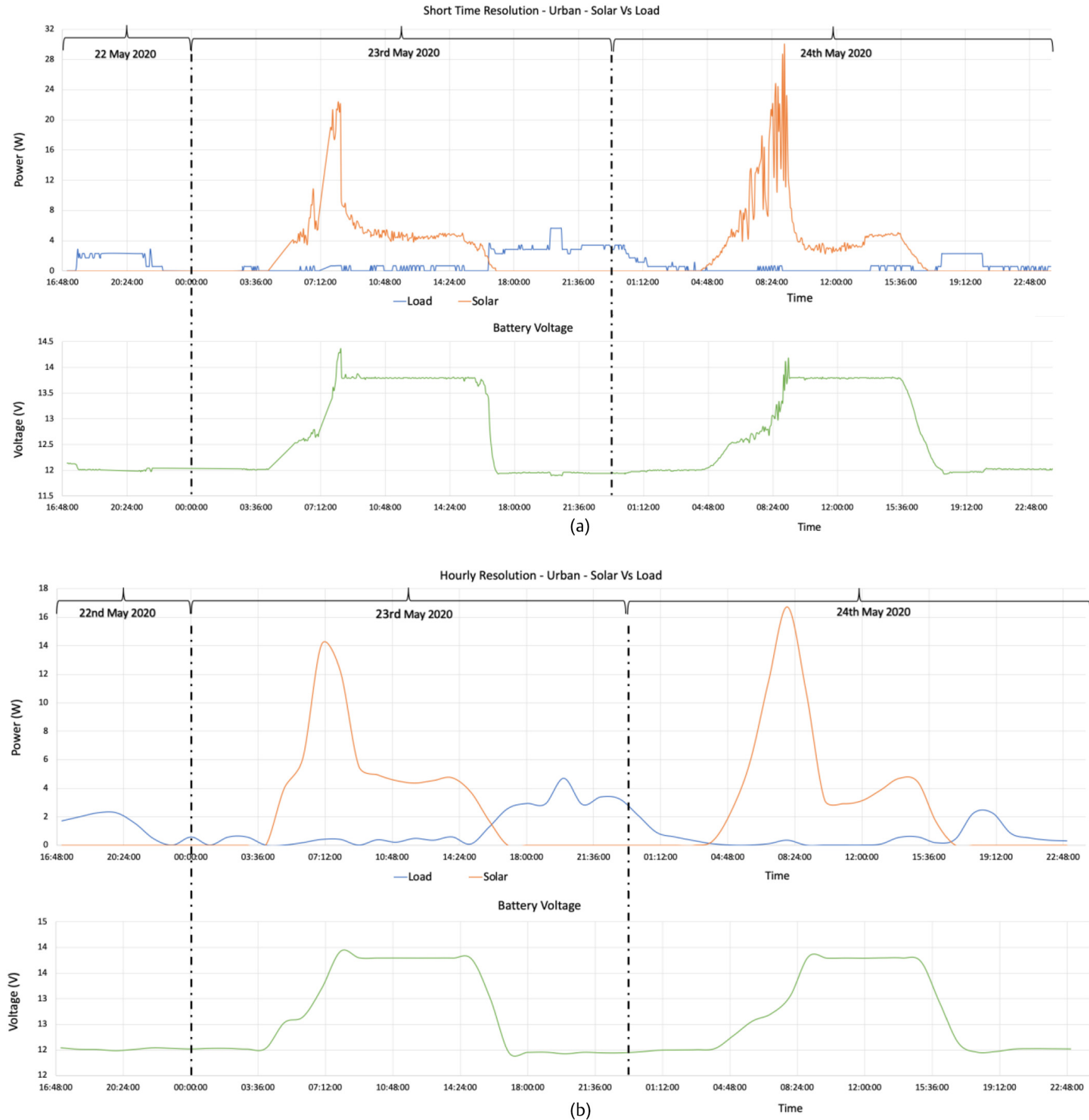

Fig. 4. Example of Daily solar data for 22nd May, 23rd May and 24th May at the Urban location. (a) For short time resolution (5-minute); (b) For hourly resolution.

As with the rural SHS, the urban households use a Lead Acid battery for storing the energy and feeding the load. The battery capacity is approximately $20 \mathrm{Ah}$ depending upon the load demand of the family, and the standard battery voltage is $12 \mathrm{~V}$. From Figure 4 , the maximum battery voltage on $23 \mathrm{rd}$ May is $14.4 \mathrm{~V}$ for a short period (topping stage) but once fully charged, the battery voltage remains constant at $13.8 \mathrm{~V}$ until there is load demand in the evening to drain the energy from the battery. The battery voltage follows a similar curve on both days, but the battery takes about one hour longer to recharge to the maximum voltage on 24th May.

Figure 5 shows the availability of surplus power at the urban location. During the summer, the output could reach close to the $60 \mathrm{~W}$, rated peak power of the solar panel. The recorded solar output from SHS nearly matches with the calculated solar production from Solcast at the beginning of the day while the battery is charging, but after 09:30, 


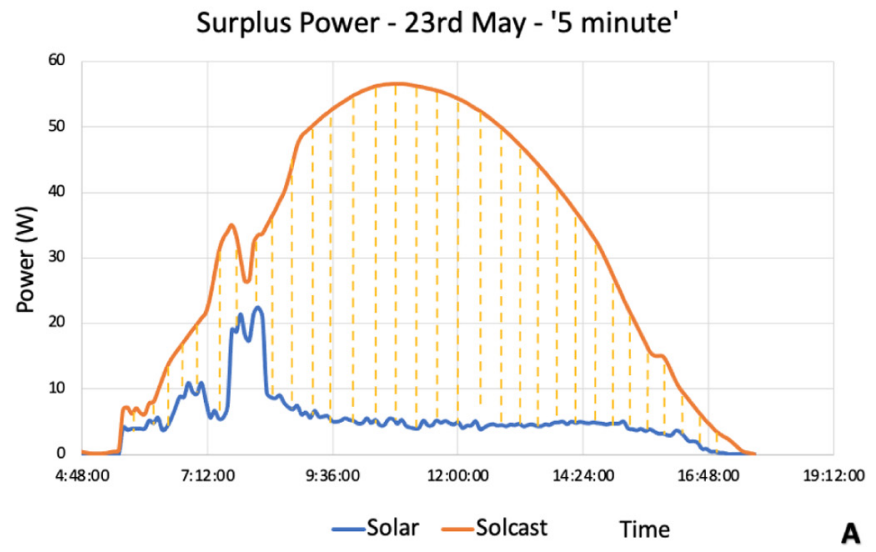

Surplus Power - 24th May - '5 minute'

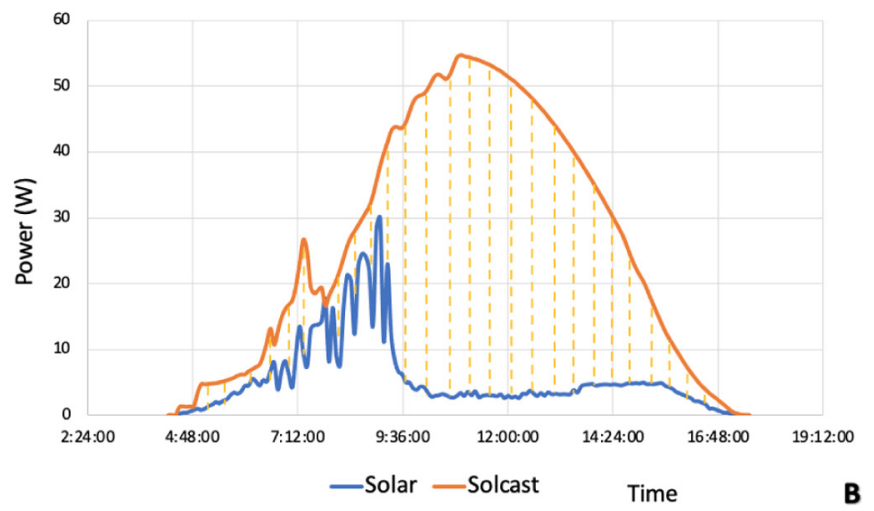

Surplus Power - 23rd May - 'Hourly'

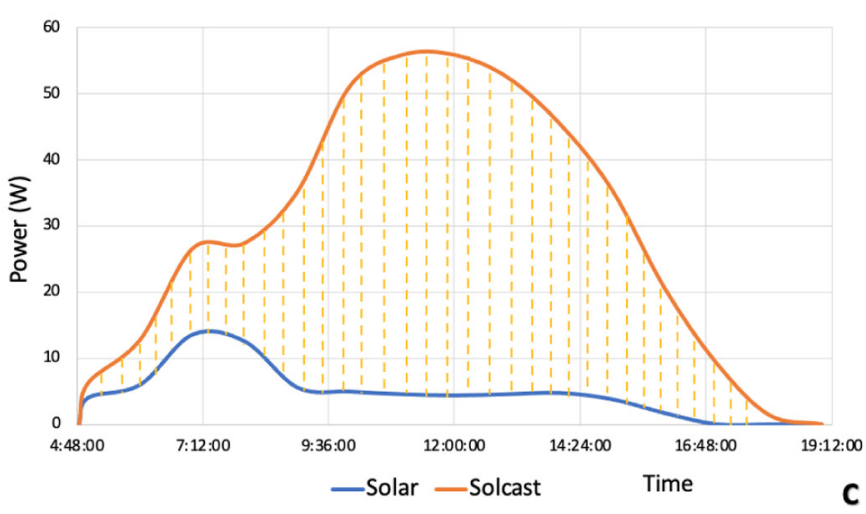

Surplus Power - 24th May - 'Hourly'

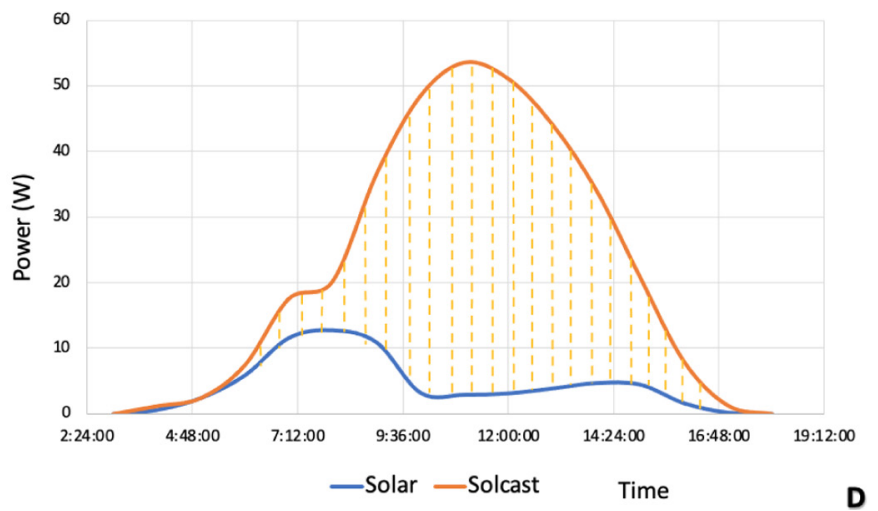

Fig. 5. Surplus Power on a 5-minute scale; (A) 23rd May, (B) 24th May and Surplus Power on an hourly scale (C) 23rd May; (D) 24th May.

the battery is fully charged, and there is no load requirement. After that time, the solar output is only used to trickle charge the battery and the remainder is surplus power.

For the 48 hours shown in Figure $5 \mathrm{~A}$ and $5 \mathrm{~B}$, the total solar energy generated from SHS is $139 \mathrm{Wh}$, whereas that calculated from Solcast on a 5 -minute scale is $753 \mathrm{Wh}$. As a result, the surplus solar is $82 \%$ using the 5 -minute time resolution. Using hourly time resolution (Fig. 5C and 5D), the total solar output is $143 \mathrm{Wh}$. The potential solar generation from Solcast is $744 \mathrm{Wh}$, giving $81 \%$ of surplus solar energy for this SHS. Again, this shows that using hourly data does not introduce a significant error in calculating surplus energy.

\subsection{Estimation of annual surplus and seasonal trends}

This section discusses the overall trends to estimate the seasonal and annual availability of surplus power for offgrid solar home systems. The data available includes consecutive data over several days in different months and at other locations within Odisha. Figure 6 illustrates the data for an urban SHS of $60 \mathrm{Wp}$ rating during June (summer). It outlines the actual solar output (orange curve) along with the load consumption (blue curve) and the potential solar generation from Solcast (green curve) from 2nd Jun to 13th Jun in Figure 6. The area shaded yellow between the green and orange curves represents the surplus solar energy.

In Figure 6, there was a gap in data collection on 7th Jun; accordingly, this day was not considered when determining the solar surplus. The load demand is mostly $2 \mathrm{~W}$ for a few hours each evening. Towards the end of the period, the solar potential is reduced due to cloudy days (pre-monsoon conditions) when there is limited surplus energy. Note that on 12 th Jun, the graph shows a time in the morning when solar output is greater than the potential. This is due to the slight difference in location between the SHS and the solar monitoring location used by Solcast, which means that cloud cover does not occur at precisely the same time.

The surplus available on sunny days 2 nd to 6 th, 9 th and 10th June are between $81 \%$ and $87 \%$. On the less sunny days of 8 th, 11 th and 13 th June the surplus power is reduced to $75 \%, 72 \%$ and $64 \%$ respectively. The cloudiest day in this period is 12 th Jun, when the solar generation potential is less than one-third of sunny days, but the SHS generation is also lower, leaving a surplus of $48 \%$. This shows that the solar module is sized for days with significant cloud cover, which often occurs during the monsoon months of July to September. 


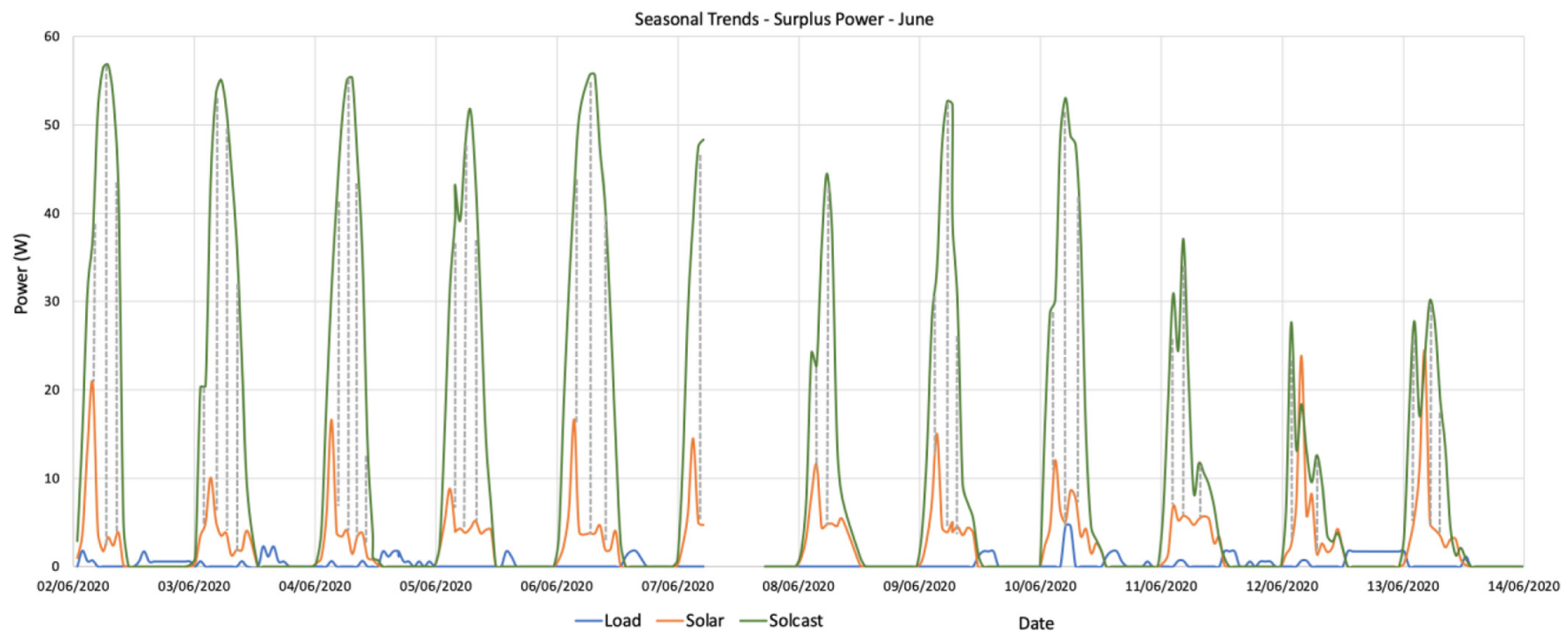

Fig. 6. Comparison of Solar power and Load Consumption for Urban SHS for 12 days in June.

Table 2. Rural SHS solar surplus trend for few days in January and February.

\begin{tabular}{llll}
\hline Date & Solar Output $(\mathrm{Wh})$ & Solar Input $(\mathrm{Wh})$ & Surplus Percentage \\
\hline $29-01-2020$ & 44 & 139 & $68 \%$ \\
$30-01-2020$ & 55 & 143 & $62 \%$ \\
$31-01-2020$ & 78 & 157 & $50 \%$ \\
$01-02-2020$ & 60 & 139 & $57 \%$ \\
$02-02-2020$ & 47 & 141 & $67 \%$ \\
$03-02-2020$ & 41 & 172 & $76 \%$ \\
$04-02-2020$ & 47 & 137 & $66 \%$ \\
$05-02-2020$ & 55 & 54 & $0 \%$ \\
\hline
\end{tabular}

Table 3. The ratio of Load:Solar (\%) for ten urban households (26th Nov to 17th Dec 2020).

\begin{tabular}{llll}
\hline Household & Total Load $(\mathrm{Wh})$ & Total Solar $(\mathrm{Wh})$ & Ratio $(\%)-$ Load:Solar \\
\hline 1 & 4618 & 5086 & $91 \%$ \\
2 & 3396 & 4038 & $84 \%$ \\
3 & 3799 & 4452 & $85 \%$ \\
4 & 1764 & 2408 & $73 \%$ \\
5 & 6067 & 6324 & $96 \%$ \\
6 & 3782 & 4433 & $85 \%$ \\
7 & 4771 & 5547 & $86 \%$ \\
8 & 2164 & 2891 & $75 \%$ \\
9 & 2505 & 3266 & $77 \%$ \\
10 & 4977 & 5321 & $94 \%$ \\
\hline
\end{tabular}

Table 2 depicts the data for a rural SHS of $40 \mathrm{Wp}$ rating during January and February (winter) to calculate the solar surplus trends. The evening load demand of the household is up to around $8 \mathrm{~W}$, whereas the average solar output averages a maximum of $13 \mathrm{~W}$ for these days.
On 5th Feb, there was significant cloud cover, resulting in low availability of surplus power, whereas the other days have $50 \%$ or more of solar surplus power available.

Table 3 represents another set of SHS data for ten offgrid households at Cuttack, an urban location in Odisha. 
Table 4. Percentage of Surplus Power available for ten different SHS from 25th Nov to 17th Dec.

\begin{tabular}{|c|c|c|c|c|c|c|c|c|c|c|c|}
\hline Date & 1 & 2 & 3 & 4 & 5 & 6 & 7 & 8 & 9 & 10 & Daily Avg. \\
\hline $17-12-2020$ & $8 \%$ & $23 \%$ & $13 \%$ & $4 \%$ & $0 \%$ & $11 \%$ & $3 \%$ & $25 \%$ & $15 \%$ & $0 \%$ & $10 \%$ \\
\hline $16-12-2020$ & $21 \%$ & $32 \%$ & $45 \%$ & $75 \%$ & $15 \%$ & $45 \%$ & $26 \%$ & $52 \%$ & $26 \%$ & $12 \%$ & $35 \%$ \\
\hline $15-12-2020$ & $19 \%$ & $32 \%$ & $22 \%$ & $69 \%$ & $16 \%$ & $34 \%$ & $28 \%$ & $34 \%$ & $28 \%$ & $12 \%$ & $29 \%$ \\
\hline $14-12-2020$ & $26 \%$ & $37 \%$ & $34 \%$ & $68 \%$ & $23 \%$ & $35 \%$ & $32 \%$ & $40 \%$ & $36 \%$ & $18 \%$ & $35 \%$ \\
\hline $13-12-2020$ & $13 \%$ & $26 \%$ & $49 \%$ & $58 \%$ & $6 \%$ & $36 \%$ & $24 \%$ & $50 \%$ & $41 \%$ & $0 \%$ & $30 \%$ \\
\hline $12-12-2020$ & $21 \%$ & $29 \%$ & $50 \%$ & $65 \%$ & $19 \%$ & $41 \%$ & $41 \%$ & $55 \%$ & $63 \%$ & $11 \%$ & $40 \%$ \\
\hline $11-12-2020$ & $22 \%$ & $35 \%$ & $50 \%$ & $65 \%$ & $19 \%$ & $50 \%$ & $42 \%$ & $49 \%$ & $46 \%$ & $13 \%$ & $39 \%$ \\
\hline $10-12-2020$ & $29 \%$ & $42 \%$ & $51 \%$ & $65 \%$ & $30 \%$ & $49 \%$ & $45 \%$ & $39 \%$ & $56 \%$ & $24 \%$ & $43 \%$ \\
\hline 09-12-2020 & $21 \%$ & $37 \%$ & $57 \%$ & $68 \%$ & $20 \%$ & $46 \%$ & $48 \%$ & $54 \%$ & $50 \%$ & $34 \%$ & $44 \%$ \\
\hline 08-12-2020 & $30 \%$ & $33 \%$ & $57 \%$ & $64 \%$ & $18 \%$ & $51 \%$ & $39 \%$ & $43 \%$ & $62 \%$ & $31 \%$ & $43 \%$ \\
\hline $07-12-2020$ & $20 \%$ & $42 \%$ & $49 \%$ & $72 \%$ & $12 \%$ & $46 \%$ & $42 \%$ & $60 \%$ & $59 \%$ & $5 \%$ & $41 \%$ \\
\hline $06-12-2020$ & $14 \%$ & $26 \%$ & $45 \%$ & $66 \%$ & $14 \%$ & $36 \%$ & $26 \%$ & $57 \%$ & $56 \%$ & $8 \%$ & $35 \%$ \\
\hline 05-12-2020 & $23 \%$ & $24 \%$ & $56 \%$ & $80 \%$ & $5 \%$ & $45 \%$ & $21 \%$ & $49 \%$ & $58 \%$ & $28 \%$ & $39 \%$ \\
\hline $04-12-2020$ & $14 \%$ & $43 \%$ & $53 \%$ & $70 \%$ & $15 \%$ & $42 \%$ & $24 \%$ & $43 \%$ & $70 \%$ & $21 \%$ & $40 \%$ \\
\hline $03-12-2020$ & $33 \%$ & $28 \%$ & $41 \%$ & $68 \%$ & $0 \%$ & $45 \%$ & $36 \%$ & $43 \%$ & $57 \%$ & $2 \%$ & $35 \%$ \\
\hline 02-12-2020 & $6 \%$ & $41 \%$ & $41 \%$ & $75 \%$ & $1 \%$ & $44 \%$ & $25 \%$ & $63 \%$ & $68 \%$ & $11 \%$ & $38 \%$ \\
\hline $01-12-2020$ & $22 \%$ & $41 \%$ & $41 \%$ & $79 \%$ & $6 \%$ & $50 \%$ & $40 \%$ & $77 \%$ & $56 \%$ & $21 \%$ & $43 \%$ \\
\hline $30-11-2020$ & $24 \%$ & $49 \%$ & $38 \%$ & $69 \%$ & $6 \%$ & $59 \%$ & $21 \%$ & $82 \%$ & $45 \%$ & $7 \%$ & $40 \%$ \\
\hline 29-11-2020 & $14 \%$ & $43 \%$ & $28 \%$ & $80 \%$ & $8 \%$ & $55 \%$ & $42 \%$ & $79 \%$ & $61 \%$ & $9 \%$ & $42 \%$ \\
\hline $28-11-2020$ & $8 \%$ & $35 \%$ & $19 \%$ & $77 \%$ & $12 \%$ & $46 \%$ & $6 \%$ & $73 \%$ & $54 \%$ & $6 \%$ & $34 \%$ \\
\hline $27-11-2020$ & $0 \%$ & $0 \%$ & $0 \%$ & $31 \%$ & $0 \%$ & $0 \%$ & $0 \%$ & $71 \%$ & $20 \%$ & $0 \%$ & $12 \%$ \\
\hline $26-11-2020$ & $0 \%$ & $42 \%$ & $0 \%$ & $32 \%$ & $0 \%$ & $0 \%$ & $0 \%$ & $41 \%$ & $0 \%$ & $9 \%$ & $12 \%$ \\
\hline Household Avg. & $18 \%$ & $34 \%$ & $38 \%$ & $64 \%$ & $11 \%$ & $39 \%$ & $28 \%$ & $54 \%$ & $47 \%$ & $13 \%$ & $34 \%$ \\
\hline
\end{tabular}

The data is for 22 days from 26th Nov to 17 th Dec 2020, which is the winter season in India. These households use similar appliances to the rural households, but the maximum output from the installed solar panel is $80 \mathrm{~W}$. The effective functioning of the SHS in these households can be determined by the ratio of load energy consumption to solar energy production, as shown in Table 3. This ratio is linked to the efficiency of the SHS, including charge controller and battery, before considering energy loss due to solar surplus. Household 5 has the highest load usage and the highest ratio $(96 \%)$ because a significant part of the power is used in the daytime when there are no battery losses. Household 4, with the least load demand, has the lowest load:solar ratio (73\%), but even this value is acceptable for SHS with a Lead-acid battery.

Table 4 represents the percentage of solar surplus available for the same households and the same 22 days in winter. The overall average is $34 \%$, much lower than the surplus in summer. There is a significant range in the data, including two days with no excess in most households. In some cases, the raw data showed negative values, probably due to the difference in cloud cover between SHS and Solcast monitoring locations since Cuttack is about $30 \mathrm{~km}$ from Bhubaneswar. Household 5, with the most prominent energy usage, has an overall surplus of only $11 \%$ and a daily range from $0 \%$ to $30 \%$. In contrast, household 4 has a general excess of $64 \%$, with a daily range from $4 \%$ to $80 \%$ during this winter period. The daily average for all ten households varies from $44 \%$ on 9 th Dec to only $10 \%$ on 17th Dec.

The trend for solar usage over the whole year, known values and interpolated data can be plotted to estimate the overall solar surplus. Splitting the year into two-month periods, the Solcast data was used to find the average solar irradiance. Based on the known values of solar surplus, the surplus for other times of year was estimated, knowing the relative value of available solar energy.

Figure 7 shows the results, which gives an average solar surplus through the year of around $50 \%$. The values for the urban and rural households are consistent with the level of solar energy available. The estimated surplus for the monsoon months of July and August is $25 \%$ based on the reduction in solar output and greater use of fans during humid weather.

\section{Enhancement of SHS to capture surplus energy}

The following section discusses potential methods to detect the surplus energy in real-time to connect low-priority loads and make better use of the available energy from offgrid SHS. Additionally, the authors discuss the problems and challenges of implementing algorithms to detect and switch the surplus power. Various additional loads that can be used to take the surplus energy have been proposed to 


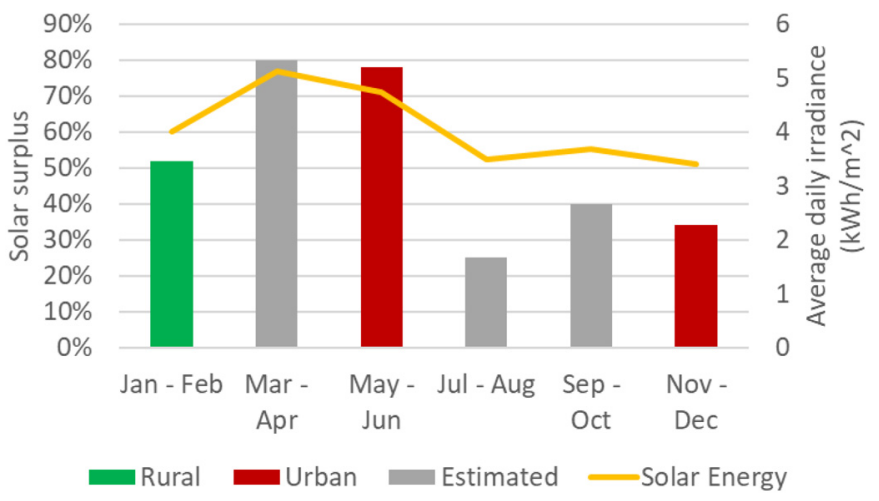

Fig. 7. Variation of Annual trends in Solar surplus SHS in Odisha, India.

produce solar power. Based on the power of the SHS reviewed in this paper, this can include surface water pumps $(75 \mathrm{~W})$, poultry incubators $(75 \mathrm{~W})$, refrigeration or chilling systems $(40 \mathrm{~W})$, freezing/ice making $(95 \mathrm{~W})$ and fan cooling/drying (less than $50 \mathrm{~W}$ ). These loads can help support income-generating activities and are all suitable for low-priority switching to operate only when surplus is available.

\subsection{Battery threshold voltage}

It can be seen from the monitored data that when the battery is fully charged. The solar module generates the power and the battery voltage rises to around $13.8 \mathrm{~V}$. If there's a load requirement and the solar generation falls below the load power (e.g., at the end of the afternoon in Figs. 2 and 4 ), the battery voltage falls rapidly to around $12 \mathrm{~V}$. Therefore, the battery voltage can be used as a trigger to detect when there is surplus solar. If a load is then connected to the system and the voltage remains high, then there is still surplus power, but if the voltage falls below a certain threshold (e.g., $13 \mathrm{~V}$ ), it indicates that the load is greater than the available surplus.

\subsubsection{Switching instability problem}

Suppose loads are switched automatically by a relay based on the battery voltage. In that case, there is a problem if the surplus power is smaller than the load because the load will switch on and off with the changes in battery voltage triggered by the additional load being connected and disconnected. With such a system, the load will switch on and off too many times, and ultimately the relay will break down and damage the circuit. Therefore, there should be appropriate delays or power measurements built into the circuit so that when there is not enough surplus, it does not allow the additional load to be connected.

One method to overcome this issue is by chopping the current and monitoring the current entering the load until the charge controller voltage comes down. This can be achieved by using small power increments based on, for example, a thyristor chopper. However, this will limit the

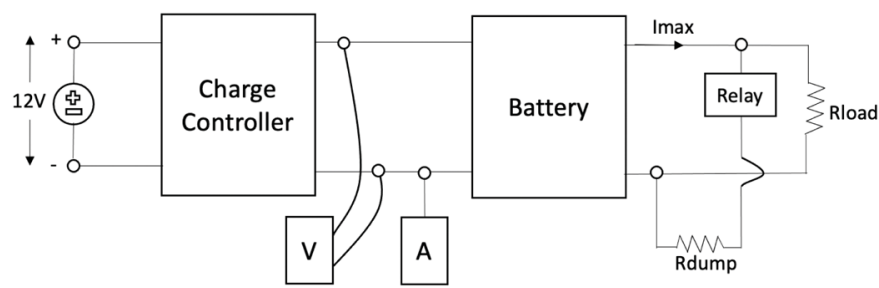

Fig. 8. Circuit diagram showing the methods to utilise the surplus energy with additional loads.

loads that can be added, as some loads will not work or will become damaged when powered through thyristor choppers.

Figure 8 is the tentative circuit diagram that can be used to design and build a device capable of utilising surplus energy with the help of additional loads. The $R_{\text {dump }}$ here is the resistance value of the additional loads that can be put on the SHS at a time of surplus energy. Feedback from the voltage measurement circuit, $\mathrm{V}$ and the current measurement A can be used to determine whether surplus loads should be connected or disconnected, as explained below.

\subsubsection{Measuring the battery voltage of the system}

It is much easier to monitor the current and voltage parameters in real-time than to measure the energy or power. Especially the voltage is relatively easy to measure, as only a voltage divider is needed to give a suitable signal for the micro-controller. The threshold battery voltage for switching on loads could be set to $13.5 \mathrm{~V}$. In contrast, the threshold for switching off could be set to $12.5 \mathrm{~V}$. If the system were to detect battery state of charge by voltage, the open-circuit voltage needs to be measured because it is this voltage that is correlated with the state of charge. This could be achieved by instantaneous disconnection of the load.

\subsection{Solar $I-V$ measurements}

The current-voltage performance characteristic of $\mathrm{PV}$ modules follows a standard form, as shown in Figure 9. An alternative method for detecting the solar surplus is to use basic voltage measurements from the system to determine the operating point and implement an algorithm to switch additional low-priority loads.

\subsubsection{Short circuit current measurement}

One method to detect the surplus power is by measuring the effective short circuit current from the solar module. A low ohm shunt resistance of known value can be momentarily connected to the system. This effectively short circuits the solar module; a measurement of the voltage across the fixed resistance will give a measure of $I_{\mathrm{SC}}$ (from Ohm's law), and this can be used to detect the available power from the solar module since there is a known ratio of current at maximum power to $I_{\mathrm{SC}}$ 
$40 \mathrm{Wp}$ module I-V characteristic

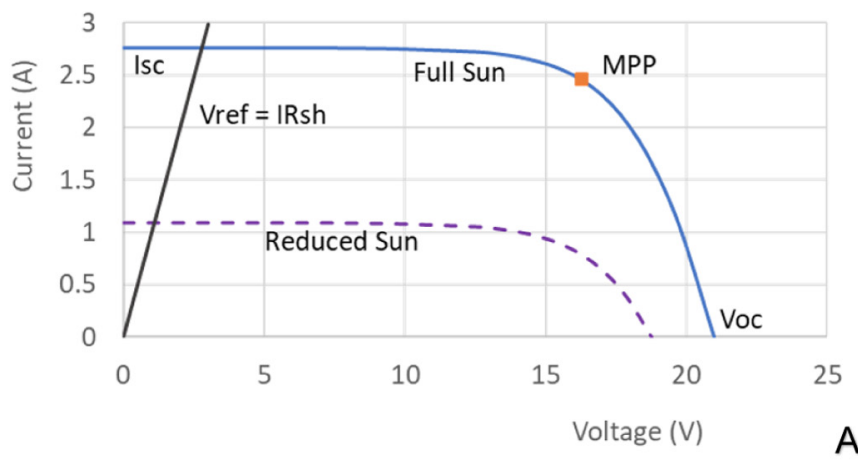

$40 \mathrm{Wp}$ module I-V characteristic

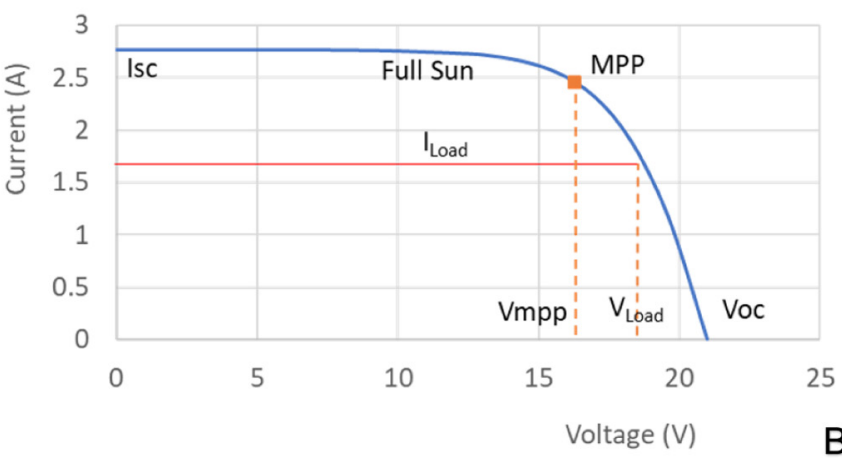

Fig. 9. Typical voltage and current curve for SHS module (A) with shunt resistance I-V characteristic; (B) showing how module voltage changes with load.

(approximately 0.9). Measurement of load current would also be needed and compared with the solar current to determine the surplus.

Figure 9a shows how the short circuit current increases with increasing solar irradiance. These changes can be monitored by the reference voltage across a shunt resistor, $R_{\mathrm{sh}}$. For example, if $R_{\mathrm{sh}}=1 \Omega, V_{\text {ref }}$ will vary from 0 to $2.8 \mathrm{~V}$ for this $40 \mathrm{~W}$ module, an ideal range for input to a microprocessor.

\subsubsection{Open circuit voltage measurement}

Another method for detecting the amount of surplus power available would be to momentarily disconnect the load to measure the open-circuit voltage, $V_{\text {oc }}$. There is a more-orless fixed ratio between $V_{\mathrm{mpp}}$ and $V_{\mathrm{oc}}$ (around 0.8 for $\mathrm{Si}$ modules). Therefore, the value of $V_{\text {mpp }}$ can be determined from the measurement of $V_{\mathrm{oc}}$. The difference between $V_{\mathrm{mpp}}$ and $V_{\text {Load }}$ will indicate the amount of surplus solar power available, as shown in Figure 9b. The load can be added up to the point that the operating voltage falls to $V_{\mathrm{mpp}}$. The voltage $V_{\text {oc }}$ and $V_{\text {Load }}$ can be measured using a voltage divider circuit and input via an $\mathrm{A} / \mathrm{D}$ converter to a microprocessor.

\section{Conclusion}

Real-time monitoring of Solar Home Systems in Odisha, India, has given an insight into the typical load usage for off-grid SHS. Although other studies have looked at energy usage of SHS, no previous studies have presented results based on detailed electrical data collection. Hourly data, made available through a collaborating company, was checked against data at 2-5 minute intervals on certain days. The use of hourly data for these households did not cause a significant error in determining the solar surplus.

From this analysis, it is estimated that, on average, $50 \%$ of the solar energy is surplus. In most homes, the primary loads are connected in the evening, and the next day the battery is recharged from the solar module. On the least sunny days, there is just enough solar energy to recharge the battery during the daytime, but most days have more sunshine, and the battery is quickly recharged. After that, the solar module trickle charges the battery and there is a significant surplus of potential solar energy that is unused, which could be used to power low-priority loads during the daytime. These include some end-uses that lead to income generating activities, such as egg incubation or crop drying. This is important because it improves the financial benefit of SHS.

The paper also presents various methods that could be used to control these low-priority loads by detecting surplus power from the SHS, using low-cost microcontroller technology. Although this would add a small cost, it would improve the overall cost-effectiveness of the systems since it could double the usable solar energy supplied from a given module size. Some further investigation is required to determine which of the proposed methods would be most effective.

Acknowledgments. The authors would like to give their special thanks to $\mathrm{Mr}$ Joel Chaney, the director of company CREATIVEnergie, Edinburgh and management leader Ms Esther Chaney for their patient help. We would also like to convey our deepest gratitude to Mr Vijay Bhopal and Mr Gareth Selby of Connected Energy, Edinburgh for sharing the solar data, as the research paper would not be completed without their support. We also acknowledge the use of data from Solcast based on initial free access for research purposes. We would also like to thank the Department of Electrical and Electronic Engineering staff, the University of Nottingham, for their guidance in taking the initial work of a Masters project through to a complete research paper.

\section{References}

1. E.-J. Quak, The cost benefits of lighting and electricity services for off-grid populations in Sub-Saharan Africa', A case study from K4D Helpdesk Report, Institute of Development Studies, Brighton, UK (2018)

2. IRENA, Off-grid renewable energy solutions to expand electricity access: an opportunity not to be missed', International Renewable Energy Agency, Abu Dhabi, UAE, 2019 
3. M.C. Pacis, J.T. Sese, H.A. Blastique, M.D.C. Casibang, Metering of Surplus Energy on PV Systems using Zigbee wireless technology, in 6th IEEE International Conference on Control Systems, Computing and Engineering, Penang, Malaysia, 27th Nov 2016

4. IRENA, Off-grid renewable energy solutions: Global and regional status and trends. IRENA, Abu Dhabi, UAE, 2018

5. H. Lestari, M. Arentsen, H. Bresseers, Sustainability of renewable off-grid technology for rural electrification: a comparative study using the LAD framework, Sustainability (2018)

6. S. Feron, Sustainability of off-grid photovoltaic systems for rural electrification in developing countries: a review, Sustainability (2016)

7. D. Palit, A. Chaurey, Off-grid rural electrification experiences from South Asia: status and best practices, Energy Sustain. Dev. (2021)

8. R. Kosonen, C. Heron, E. Marckx, Using batteries to ensure clean, reliable and affordable universal electricity access: a guide for energy decision makers, Alliance for Rural Electrification - Position paper, Energy Storage Campaign (2013)

9. K. Berzina, I. Zicmane, A. Sobolevkis, Optimal PV electrical energy storage of Building's communal space lighting, Conference IEEE International Conference on Environment and Electrical Engineering and2017 IEEE Industrial and Commercial Power Systems Europe (EEEIC/ IECPS Europe); doi: 10.1109/EEEIC.2017.7977582

10. A.H. Khan, A. Islam, M. Islam, M. Saifur Rahman, A systematic approach to find the optimal tilt angle for meeting the maximum energy demand of an isolated area, in 2nd International Conference on Electrical Engineering and Information on Communication Technology (ICEEICT), 2015

11. Poor People's Energy Outlook 2019: Enabling energy access: from village to nation, Practical Action, 2019

12. A.A. Eras-Almeida, M. Fernandez, J. Eisman, J.G. Martin, E. Caamano, M.A. Egido-Aguilera, Lessons learned from Rural Electrification Experiences with Third Generation
Solar Home Systems in Latin America: Case Studies in Peru, Mexico and Bolivia' Sustainability 11, 7139 (2019)

13. S. Tesema, G. Bekele, Resource assessment and optimisation study of efficient type hybrid power system for electrification of Rural District in Ethiopia, Int. J. Energy Power Eng. (2015)

14. S.A. Chowdhury, M. Mourshed, Off-grid electrification with solar home systems: an appraisal of the quality of components, Renew. Energy 97, 585-598 (2016)

15. P.J.M. Thomas, P. Sandwell, S.J. Williamson, P.W. Harper, A PESTLE analysis of solar home systems in refugee camps in Rwanda, Renew. Sustain. Energy Rev. 143 (2021)

16. J. Urpelainen, S. Yoon, Solar products for poor rural communities as a business: lessons from a successful project in Uttar Pradesh, India, Clean Techn Environ Policy 18, 617-626 (2016)

17. M. Barman, S. Mahapatra, D. Palit, M.K. Chaudhury, Performance and impact evaluation of solar home lighting systems on the rural livelihood in Assam, India, Energy Sustain. Dev. 38, 10-20 (2017)

18. Y.A. Munoz Maldonado, C.E. Vera Suarez, M. de los Angeles Pinto Calderon, System for performance assessment of Solar home systems, Industry 4.0 for Energy, Water, Air and Biorefineries; doi: 10.16925/ecam.03

19. M. Nasir, M. Anees, H.A. Khan, I. Khan, Y. Xu, J.M. Guerrero, Integration and decentralized control of standalone solar home systems for off-grid community applications, IEEE Trans. Ind. Appl. 55, 7240-7250 (2019)

20. Availability of Solar data, https://creativenergie.co.uk (accessed Dec 2020)

21. Solar data raw form, https://connectedenergy.net/cloudsolar (accessed Jan 2021)

22. Solar irradiance values from NASA, https://power.larc.nasa. gov/data-access-viewer/ (accessed Jan 2021)

23. Solar irradiance values from Solcast, https://solcast.com (accessed Jan 2021)

24. Information related to the additional loads at https://www. lightingglobal.org/wp-content/uploads/2019/09/PULSEReport.pdf (accessed April 2021) 